\title{
AS LEIS DIETÉIICAS JUDAICAS: UM PRATO CHEIO PARA A ANTROPOLOGIA
}

\author{
Marta F. Topel \\ Universidade de São Paulo - Brasil
}

Resumo: $O$ objetivo deste texto é compreender as características principais do complexo sistema judaico relativo às leis alimentares. Nesse afã, serão discutidas: 1) a sua função social perante a incorporação de novos membros à ortodoxia judaica, com a decorrente reformulação das fronteiras do grupo; e 2) a sua função simbólica no sistema religioso judaico, que dá ênfase à prática ritual em lugar de crenças ou atos de fé. Ambas questões serão ilustradas a partir de dados obtidos no trabalho de campo desenvolvido com os novos judeus ortodoxos de São Paulo de 1999 a 2001.

Palavras-chave: etnicidade, judaísmo, religião, simbolismo.

Abstract: The aim of this paper is to understand the main features of the complex Jewish system of dietary laws. With this in mind, the following topics will be discussed: 1) their social function as to when new members join Jewish orthodoxy, with the resultant reformulation of the group boundaries, and 2) their symbolic function in the Jewish religious system, which gives more emphasis to ritual practices rather than beliefs or faith. These two topics will be illustrated with the data gathered through a long fieldwork carried out among the new orthodox Jews of São Paulo during the years of 1999 through 2001.

Keywords: ethnicity, judaism, religion, simbolism.

Identidade étnica, consumismo e comida na modernidade tardia: algumas reflexões

Como bem assinala Buckser (1999) em relação aos Estados Unidos asseveração que podemos extrapolar facilmente ao Brasil -, os norte-americanos costumam tirar suas receitas diárias de livros de cozinha ou de 
revistas especializadas, e não dos segredos transmitidos por avós ou bisavós. Quando a questão em foco é a comida étnica, ela é preparada principalmente para acompanhar festas e celebrações extraordinárias.

Ambas tendências constituem uma característica do advento da modernidade tardia, como a chamaria Giddens (1991), que socavou as velhas estruturas e redes de pertença, fazendo com que as concepções identitárias do indivíduo perdessem grande parte de seu sentido, para transformar-se em contingentes, dependendo cada vez mais de escolhas e manipulações individuais, em lugar de estarem enraizadas numa ordem social e historicamente estabelecida. Nesse cenário, não surpreende que o consumo adquira uma importância progressiva na forma como as pessoas se definem a si mesmas, na medida em que o fato de consumir tenta estabelecer e expressar idéias sobre aquele sujeito que demonstra preferência por alguns bens em detrimento de outros, adquirindo um papel significativo na formação de identidades.

No que diz respeito à comida, uma de suas características distintivas é a capacidade simbólica para expressar relações e pertenças grupais. Assim, a comida é uma construção cultural consumida por indivíduos; e o ato de comer envolve a escolha do sujeito em relação a um grupo específico. É nesse sentido que as comidas étnicas oferecem um rico jogo de metáforas através das quais se expressam as relações dos sujeitos com um grupo particular. Esse processo fica mais evidente em comunidades novas, pequenas, minoritárias, ou nas quais há um significativo número de novos adeptos, a exemplo das comunidades religiosas que perseguem, de uma forma ou de outra, a incorporação de novos membros. E se bem o que distingue as leis alimentares judaicas é formar parte de um sistema simbólico-ritual que constrói o mundo cotidiano dos atores sociais, em marcada oposição aos costumes e leis que em outras culturas regem os jejuns e as comidas prescritos para celebrações extraordinárias, ainda assim podemos afirmar que de forma similar a estes, as leis alimentares judaicas fazem públicas filiações religiosas e culturais. De fato, na sua mais singela modalidade, as leis de pureza e impureza que prescrevem a dieta dos judeus ortodoxos constituem um exemplo de como o ato mais mundano e rotineiro, como o de comer, torna-se parte medular da experiência religiosa. Por sua vez, e como bem assinala Bell (1997, p. 120) em relação às celebrações nas quais a comida tem um papel destacado: 
A participação num banquete é um meio ritual comum para definir e reafirmar o alcance pleno da comunidade humana e cósmica. Tanto se uma comunidade é rigidamente hierárquica ou fundamentalmente igualitária, o princípio de uma comida compartilhada a marca enquanto comunidade. ${ }^{1}$

O objetivo deste trabalho é indagar a partir de algumas características do complexo sistema de leis alimentares judaicas, tendo como pontos de partida: 1) a sua função social no que diz respeito à incorporação de novos membros à ortodoxia judaica, os baalei teshuvá ou novos ortodoxos, com a decorrente reformulação das fronteiras do grupo; e 2) a sua função simbólica no sistema ortodoxo judaico, caracterizado como a expressão paradigmática de uma religião ortoprática, na qual ética e ritual se entrelaçam de forma inextricável, levando a definir o judaísmo como a religião da prosa e não da poesia, da comemoração da cotidianeidade e não do pathos inerente a momentos extraordinários (Sacks, 1991).

\section{Interdicões e recomendações, ou das leis e costumes alimentares exigidos de um judeu pio}

A década de 90 constitui uma marca divisória no judaísmo paulistano, uma vez que foi a partir desse momento que um número significativo de judeus laicos e liberais abraçou a ortodoxia, reformulando em grande medida o perfil da comunidade judaica de São Paulo. ${ }^{2}$ Esse fenômeno, que consolidou-se nos últimos anos, não obedece a um crescimento vegetativo, e sim à incorporação de novos membros ao grupo: os baalei teshuvá. ${ }^{3}$ Uma expressão dessa mudança observa-se facilmente na reconfiguração do espaço judaico paulistano, com a constante criação de novas instituições orto-

\footnotetext{
${ }^{1}$ No original: Shared participation in a food feast is a common ritual means for defining and reaffirming the full extent of the human and cosmic community. Whether that community is conceived to be rigidly hierarchical or fundamentally egalitarian, the principle of sharing food marks it as a community. (Tradução minha).

${ }^{2}$ Cf. Topel, M. (2003) e O Movimento de Teshuvá em São Paulo e o Esgotamento do Judaísmo Secular no Brasil: Algumas Reflexões, também da autora, a ser publicado.

${ }^{3}$ Baal Teshuvá (sg); baalei teshuvá (pl): expressão hebraica utilizada para designar os judeus laicos que abraçaram a ortodoxia.
} 
doxas, como yeshivot, ${ }^{4}$ kolelim,${ }^{5}$ creches, sinagogas, mikves, ${ }^{6}$ centros de estudo informal, bibliotecas e fitotecas circulantes, restaurantes e supermercados kasher, ${ }^{7}$ e espaços de lazer. Um dado não menos importante é o aumento do número de rabinos ortodoxos atuantes na cidade. Nesse sentido, se na década de 50 São Paulo contava com menos de dez rabinos ortodoxos, hoje, segundo apontam dados encontrados na Federação Israelita do Estado de São Paulo (FISESP) ${ }^{8}$ conta com mais de uma centena.

A longa caminhada desses homens e mulheres para se transformarem em judeus pios implica o aprendizado do complexo sistema ritualístico judaico ortodoxo, no qual as leis dietéticas detêm um papel central. Assim, é importante lembrar que para a ortodoxia judaica é considerado membro do grupo aquele judeu que cumpre estritamente os preceitos ligados ao descanso sabático, às leis de pureza familiar e às leis que regem o princípio da kashrut, ou leis dietéticas. Em síntese: ser judeu ortodoxo não está relacionado com um ato de fé, e sim com seguir à risca os 613 preceitos ditados pelo código de leis conhecido como Halachá (em hebraico: caminho).

Kasher significa apto, idôneo, e constitui o termo utilizado para designar não só as comidas devidamente preparadas para o consumo dos judeus pios, mas também objetos e pessoas. Assim, na tradição judaica se diz que os rolos da Torá ou os filactérios são kasher quando obedecem todos os requisitos prescritos pela Halachá, e as testemunhas de uma arbitragem judicial, conhecida como din torá, são kasher se se demonstra a sua honestidade e o fato de serem judeus observantes.

No que diz respeito à comida, ela pode ser considerada não kasher por diferentes motivos, que incluem desde as espécies envolvidas (como por exemplo, a proibição do consumo de carne suína) à forma com que o alimento é processado (a mistura de leite e carne ou o abatimento de modo impróprio do animal consumido, principalmente, no que diz respeito à interdição em ingerir sangue animal), ou questões relativas ao tempo (como a ingestão de alimentos cozinhados no sábado). Porém, manter uma dieta

\footnotetext{
${ }^{4}$ Yeshivot: (hebraico): plural de yeshivá: academia de estudos religiosos para jovens.

${ }^{5}$ Kolelim: (hebraico): plural de kolel: academia de estudos religiosos para homens casados.

${ }^{6}$ Mikve: (hebraico): ritual de purificação e casa de banhos onde o mesmo se realiza.

${ }^{7}$ Kasher: (hebraico): termo que designa que um alimento está apto para o consumo de um judeu pio.

${ }^{8}$ Organização-teto da comunidade judaica paulistana.
} 
kasher implica colocar em prática uma complexa lista de leis e costumes, e um adestramento cuidadoso para não violar nenhuma delas. A sua mera enunciação tomaria centenas de páginas. Optei, então, por enumerar algumas das interdições encontradas no Shulchan Aruch ${ }^{9}$ com o intuito de familiarizar o leitor alheio ao complexo sistema das leis alimentares judaicas.

Alimentos proibidos ${ }^{10}$

A Lei de Moisés proíbe o uso do quarto traseiro, inclusive dos animais puros (Gen. XXXII:33), com a ressalva de que as partes proibidas e os vasos sangüíneos tenham sido devidamente removidos. A maioria dos açougueiros sabem como limpar os quartos dianteiros, mas não os traseiros. Conseqüientemente, usamos somente a carne do quarto dianteiro e nos abstemos de usar a do traseiro.

A proibição de comer sangue foi estendida aos ovos, e o sangue que há neles está proibido. É proibido comer os ovos que contenham manchas de sangue, por isso, o ovo tem de ser bem examinado antes de ser utilizado na preparação de alimentos.

É costume marcar todos os utensílios utilizados para os laticínios, de forma que não possam ser confundidos com os destinados para a carne.

Se a pessoa tem ingerido alimentos preparados nem com carne nem com gordura de carne, mas que têm sido cozinhados numa panela utilizada para cozinhar carne, ainda que a panela não tenha sido purificada antes, a pessoa tem a permissão de comer laticínios imediatamente depois.

Não é possível, ritualmente, purificar os utensílios utilizados para laticínios com o objetivo de que depois possam ser aptos para o uso de carne. Tampouco se podem purificar utensílios utilizados para carne com o fim de usá-los para laticínios.

${ }^{9}$ O Shulchan Aruch (em hebraico: a mesa preparada) constitui uma codificação da Lei Judaica, compilada pelo rabino Iosef de Karo no século XVI. As leis e vereditos contidos nesse texto são aceitos com unanimidade por todas as correntes contemporâneas do judaísmo ortodoxo.

${ }^{10}$ As leis da kashrut relativas aos alimentos se encontram no capítulo III da segunda parte do Shulchan Aruch, que leva por nome "O lar judaico". A tradução do espanhol é da autora. 
É estritamente proibido comer ou beber qualquer coisa que contenha minhocas ou ácaros.

A água consumida deve ser filtrada mediante uma tela de fina filigrana, capaz de excluir o menor inseto.

$\mathrm{O}$ vinagre que contém gusanos é inapto para ser usado, ainda que tenha sido filtrado, porque se acredita que o gusano menor do vinagre atravessará qualquer tela.

\section{A salgadura da carne}

O Todo-Poderoso mostrou-se muito enfático em seu mandamento de que nos abstenhamos de comer o sangue do animal e das aves de curral. Repetiu este mandamento várias vezes em Sua Lei (Gen. IX:4; Lev. XVII:14; Deut. XII:16, 23-24; XV:23). Em conformidade, nossos sábios talmúdicos têm estipulado uma lei que determina que, com o objetivo de remover de forma efetiva o sangue da carne, esta deve ser deixada de molho para abrir os poros e, logo, salgada, a fim de extrair todo o sangue.

Antes de salgar a carne, ela deve ser lavada com água. A carne deve ser deixada de molho e totalmente submergida em água durante meia hora. Toda parte na qual se advirta uma partícula de sangue deve ser perfeitamente lavada com a água na qual foi deixada de molho.

A vasilha utilizada para deixar a carne de molho não deve ser empregada na preparação de nenhum outro alimento. Conseqüentemente, é necessário utilizar uma vasilha especial para deixar a carne de molho. A carne deve permanecer no sal durante uma hora mas, em caso de emergência, serão suficientes vinte e quatro minutos.

Imersão de vasilhas

Os copos e vasilhas novos, de vidro ou de metal, destinados a ser utilizados num lar judaico, devem ser santificados para tal fim mediante sua imersão em água corrente. Antes da imersão, deve-se pronunciar a seguinte benção: "Bendito sejas, ó Senhor, nosso Deus, Rei do Universo, que nos tens santificado por teus mandamentos, e nos tens ordenado o referente à imersão das vasilhas". 
As vasilhas de madeira, argila e porcelana não devem ser submergidas, mas se têm asas de metal ou se estão revestidas de louça por dentro, devem ser submergidas sem pronunciar a benção.

Não se pode confiar a um menor, seja varão ou mulher, o cumprimento do ritual de submergir vasilhas.

É proibido submergir vasilhas no sábado ou por ocasião de uma festividade.

Mas se essas são algumas das leis básicas para manter uma dieta estritamente kasher, é importante salientar ainda que uma das características distintivas do judaísmo ortodoxo é a contínua incorporação de novas leis e costumes a seu código legal, que permitam aos judeus pios se beneficiarem - ainda que parcialmente e sob o guia da Halachá - dos avanços tecnológicos, também dos relativos à alimentação. Uma outra questão de significativa relevância diz respeito aos modos através dos quais os novos ortodoxos são iniciados no complexo sistema da kashrut. Em relação a esse tópico, nos últimos anos foram traduzidos diversos manuais para o português, cujo objetivo é ensinar seus princípios básicos aos baalei teshuvá brasileiros. Por outro lado, as revistas veiculadas pelas congregações ortodoxas $^{11}$ contêm ensinamentos, dicas e receitas em relação à dieta, tanto a cotidiana, que deve seguir uma família ortodoxa, como a que caracteriza as celebrações religiosas do calendário judaico. ${ }^{12}$ Escritas numa linguagem mais próxima aos novos ortodoxos que a utilizada no Shulchan Aruch, constituem o meio através do qual os rabinos paulistanos tentam explicar não só as interdições que devem ser respeitadas, mas também os rituais necessários que transformam uma comida numa refeição apta para o consumo de um judeu observante. Dessa forma, ensinamentos de como devem ser recitadas as bênçãos correspondentes a cada refeição, bem como explicações sobre os utensílios proibidos e permitidos para cada alimento e para cada ocasião, aparecem com frequiência nas revistas mencionadas.

Vejamos como um rabino discorre sobre as múltiplas interdições decorrentes da proibição de misturar carne e leite. Acredito que citá-lo em

${ }^{11} \mathrm{Na}$ atualidade, circulam em São Paulo pelo menos quatro revistas mensais veiculadas por distintas congregações ortodoxas. Essas publicações são gratuitas e "entregues em domicílio".

${ }^{12}$ É importante mencionar a existência, em São Paulo, de pelo menos um Departamento de Kashrut. Ele depende do Comitê Rabínico das Comunidades Chabad do Brasil. 
extenso será ilustrativo, uma vez que colocará em evidência a complexa e rigorosa parafernália ritual à qual devem se acostumar os baalei teshuvá. Assim, após explicar os princípios básicos que violariam o preceito supracitado - cuja fonte é o versículo bíblico "não cozinharás o cabrito no leite de sua mãe" (Êx: XXII:19), o rabino Shamai Ende ${ }^{13}$ acrescenta as respectivas definições do que se entende por carne, por leite, e por parve. ${ }^{14}$ Imediatamente, o mencionado rabino pareceria se adiantar às possíveis dúvidas ou tropeços de um novato, levando em consideração, entre outros, problemas e soluções relativos aos horários e utensílios idôneos que devem ser respeitados numa dieta kasher. Eis algumas de suas recomendações:

Se alguém comer carne, ou um alimento que foi cozido ou misturado junto com carne (mesmo que esta não seja ingerida), deve esperar seis horas para ingerir leite ou alimentos cozidos ou misturados com leite. Porém, para comer um alimento neutro cozido em panela de carne, totalmente limpa de vestígios, não é preciso esperar seis horas.

Se algo parve é cozido em panela de leite, totalmente limpa de vestígios, este alimento pode ser ingerido depois da carne (não junto).

Ao ingerir leite ou derivados não há necessidade de esperar seis horas antes de comer carne; basta apenas enxaguar a boca, comer pão ou outro alimento seco e beber algum líquiido.

Ao comer carne após leite ou vice-versa, mesmo esperando o tempo citado, a mesa onde foi ingerido o alimento deve ser limpada, para não restar vestígios. Todos os utensílios usados na refeição devem ser retirados. Toalhas de mesa diferentes devem ser usadas para leite e carne. Duas pessoas conhecidas não devem comer, ao mesmo tempo, uma carne e a outra leite, à mesma mesa, mesmo em utensílios separados, salvo se houver uma separação. Ou seja, cada um come em toalha separada (Ende, 1999, p. 22).

Se a pessoa não sabe que berachá [benção] recitar sobre certo alimento, não pode, a princípio, recitar Sheacol (a benção que inclui automa-

\footnotetext{
${ }^{13} \mathrm{O}$ rabino Shamai Ende pertence à corrente ortodoxa Chabad-Lubavitch e, durante anos, foi o responsável pela coluna "Comida Kasher", encontrada na revista Chabad News.

${ }^{14}$ Em hebraico: alimento neutro.
} 
ticamente todos os tipos de bênçãos), pois tem o dever de recitar a bênção específica. Se não sabe, não deve ingerir o alimento até perguntar a um conhecedor a bênção a ser recitada (Ende, 2001, p. 22).

Apesar desse mapeamento sumário, acredito ser possível perceber a complexidade do sistema que tipifica as leis alimentares judaicas. Há, porém, uma outra questão que é importante salientar: da perspectiva da tradição judaica, todos os preceitos contidos na Halachá têm como objetivo último respeitar a vontade divina. Em relação às leis alimentares, o rabino Hayim Halevy Donin (1985, p. 114) sintetiza esse princípio da seguinte forma:

O judeu observante não guarda as leis da kashrut porque ficou entusiasmado por seus detalhes peculiares, nem porque lhe proporciona prazer, nem porque as considera saudáveis e nem porque a Bíblia lhe oferece boas razões, mas sim porque para ele são Mandamentos Divinos e ele se submete à vontade Divina e à disciplina de sua Fé.

Em outras palavras, tentar procurar benefícios secundários às leis alimentares, sejam eles nutricionais ou de higiene, é distanciar-se do código ético-ritualístico que lhes deu origem.

A esses critérios devem se acrescentar dois conceitos hebraicos que são fundamentais para compreender o princípio que guia as leis dietéticas judaicas: tahor (puro) e tamé (impuro), ambos utilizados para caracterizar uma determinada condição espiritual e moral - do povo, do indivíduo, do Templo - mas nunca utilizadas para descrever limpeza ou sujeira físicas. Nesse sentido, apesar do código bíblico referente à kashrut conter indícios de uma preocupação com doenças e danos orgânicos que possam transformar um animal em não apropriado para o consumo dos judeus - salientando-se aqui motivos ligados à higiene e à saúde -, não são esses os princípios inerentes à obrigação de manter uma dieta kasher. Como bem assinala Douglas (1966), seria no mínimo esquisito pensar em Moisés como um administrador da higiene do povo judeu. Além do mais, se como fora mencionado, a única razão para seguir os princípios da kashrut é o respeito à vontade divina, devemos também destacar as exortações à santidade exigida do povo judeu, aparecidas no texto bíblico quando são enumeradas as leis alimentares. Assim, o trecho do Levítico que classifica os animais para 
consumo em puros e impuros, acaba com os seguintes versículos: "Pois sou, Iahweh, o vosso Deus. Fostes santificados e vos tornastes santos, pois que eu sou santo; não vos torneis, portanto, impuros com todos esses répteis que rastejam sobre a terra. Sou eu, Iahweh, que vos fiz subir da terra do Egito para ser o vosso Deus: sereis santos, porque eu sou santo" (Lev.: 11:44-45).

Retomarei este tópico na análise dos textos de Mary Douglas e sua interpretação da função simbólica intrínseca aos regulamentos de pureza e impureza do código mosaico. Por ora, é suficiente observar que, à semelhança de outros sistemas de símbolos e rituais, seria mais do que fecundo abordar as leis alimentares judaicas como parte de um todo mais abrangente; no nosso caso, à luz do princípio de kashrut que rege as relações sexuais entre judeus observantes. Contudo, na medida em que tal propósito extrapola os objetivos deste trabalho, considero suficiente citar as palavras de um rabino ortodoxo, com o fim de compreender a centralidade que dentro do judaísmo ortodoxo têm as leis dietéticas:

Viver de modo kasher é viver como judeu. Isto faz com que todo o estilo de vida seja único e distintivo vis-à-vis o mundo exterior. A kashrut, indubitavelmente, constitui o baluarte contra a assimilação (Grunblatt, [s.d.], tradução e grifo meus).

Todavia, após a emancipação dos judeus a partir do século XIX, o judaísmo como religião e cultura, e a grande maioria dos judeus, se desenvolveram fora do marco da ortodoxia, isto é, e para os fins que agora nos interessam, completamente afastados de, ou rebelados contra, o rígido código de leis ortodoxo, dentre as quais as leis dietéticas. Contudo, o renascimento da ortodoxia nas últimas décadas - tanto em Israel como na diáspora - com a decorrente co-optação de novos membros, gerou alguns conflitos e não poucos paradoxos. Assim, se as leis dietéticas durante milênios tiveram como função social estreitar as fronteiras do grupo, separando judeus de não-judeus, hoje presenciamos um efeito contrário: a adoção da kashrut por parte dos baalei teshuvá não só separa judeus de judeus, mas pais de filhos. 


\section{Comer ou não comer? A incorporação da kashrut entre os novos ortodoxos de São Paulo}

De fato, na pesquisa que venho desenvolvendo há três anos sobre o movimento de teshuvá em São Paulo, as dezenas de encontros que tive com novos ortodoxos, e com seus parentes de primeiro grau que não abraçaram a ortodoxia, deixaram claro que um dos conflitos mais relevantes no processo de "re-etnização" religiosa pelo qual passaram alguns membros da família está relacionado diretamente ao rigor do cumprimento das leis dietéticas. Os depoimentos que seguem são ricos em informações e ilustrativos de muitos outros:

Hoje é muito difícil eu ir na casa de alguém, de amigos e até de parentes. Muita coisa acabou. Porque se eu for na casa de alguém, as pessoas se incomodam pelo fato de eu não comer. Eu, por exemplo, trabalho num escritório só de judeus, mas sou a única religiosa. $\mathrm{Na}$ hora do almoço, eu tenho a minha comida que trago de casa. E eu penso "vocês comam o que vocês quiserem, desde que vocês não achem que eu sou estranha". Mas eles me acham estranha...

Veja só que coisa! Quando vamos com meu filho na casa dos avós para comer, ele tem que levar daqui de casa tudo descartável. E quando ele me falou que queria ser kasher, a primeira coisa que eu fiz foi pegar dois armários da cozinha, de um lado, leite, do outro, carne. Eu comprei tudo para ele separado: três panelas de carne, três panelas de leite, pratos, talheres, copos, tudo! Queria que ele se sentisse seguro em casa... Mas ele quase nunca come em casa, e quando o faz, come outra comida, preparada por ele... Um dia eu quis fazer uma surpresa, porque ele sempre gostou da minha comida. Então, comprei um frango kasher no supermercado dos religiosos: paguei uma fortuna! Peguei a panela dele e pedi para a empregada preparar o frango. Mas ele não pôde comer porque foi um gentio quem acendeu o fogo. Eu nunca soube disso na minha vida! E isso que fui criada num ambiente judaico. O que vou te dizer? Foi um drama: eu só chorava, eu só chorava... 
Outros testemunhos apontam as dificuldades em seguir as leis da kashrut em marcos não judaicos, como, por exemplo, no espaço de trabalho. Foi da seguinte maneira que uma nova ortodoxa me explicou a sua experiência nessa área:

Eu trabalhei na Quaker durante um ano e meio, me estava dando super bem lá: eu era a única nutricionista e poderia ter subido bastante. Só que aí começou o problema da kashrut. Porque eu tinha que degustar as comidas. No início eu tentei dar uma enganada, separar carne de leite, sei lá; mas em seguida compreendi que não estava certo isso. Por outro lado, também estava todo o negócio das festas judaicas: eu tive que faltar treze dias nesse ano e depois, bom, depois o horário do shabat. Eu pedi para sair às cinco e pouco nas sextas-feiras, conversei com o gerente. Mas a Quaker é uma empresa muito grande e não puderam abrir uma exceção para mim. Não teve como! Daí eu tive que pedir as minhas contas e sair. Fiquei muito chateada porque entrar lá foi super difícil: fui a única entre onze meninas. Mas eu falo que estou optando por esta vida e não tem como... E graças a Deus, agora comecei a trabalhar numa escola judaica, agora dou aula ali.

Esses dados revelam que o cumprimento das leis dietéticas, principalmente por pessoas que as adotaram em idade adulta, constitui um foco de tensões. Assim, quem escolheu o caminho da ortodoxia, mas vive, isto é, trabalha, estuda, viaja e come, no marco da sociedade mais ampla, se vê confrontado com o dilema de: ou manifestar abertamente a sua identidade judaica, o que equivale a rejeitar a comida oferecida pelos seus pares não judeus, ou transgredir um princípio básico do judaísmo. A primeira opção não é menos dura do que a segunda, se partirmos do pressuposto de que se trata de pessoas que também se definem como brasileiras, e para as quais é difícil e embaraçoso quebrar as regras de etiqueta vigentes no Brasil, além de colocar numa situação desagradável amigos e companheiros de trabalho.

Do ponto de vista da antropologia, esse conflito de identidades poderse-ia definir como uma ambivalência entre crenças e práticas, por um lado, e entre uma identidade intra-grupal e uma exo-grupal, por outro (Heilman; Cohen, 1989). Nesse sentido, o conflito identitário dos baalei teshuvá se 
expressa em que, ao mesmo tempo em que se esforçam por seguir à risca a Halachá, considerada o pré-requisito para lograr a membresia no seio do judaísmo ortodoxo, se vêem confrontados com dificuldades quando a nova identidade é assumida fora do grupo. Esse dualismo, a meu ver, deve ser considerado parte integrante do processo de "re-etnização" religiosa por que passam os baalei teshuvá, e que, segundo o esquema de Merton e Barber (1963, p. 96), se enquadra em dois dos tipos de ambivalência sociológica (social ambivalence) por eles analisados. Com efeito, observamos a expressão dessa ambivalência sociológica de duas formas. A primeira, gerada pelo arranjo desarmonioso de status diferentes num mesmo ator social - neste caso, um ator social que aspira ser, simultaneamente, um judeu observante e um brasileiro urbano -, fenômeno que o leva a desenvolver sentimentos confusos e criar um reajuste de comportamento; a segunda ambivalência observa-se na necessidade de se adaptar a valores contraditórios demandados pela pluralidade das culturas em questão.

Perante esse dilema, e no intuito de resolver os conflitos dele decorrentes, observei que os novos ortodoxos adotam diversas estratégias. No primeiro momento do processo de "re-etnização" religiosa, a escolha é por uma solução de compromisso, criando um sistema paralelo que se resume em manter uma dieta kasher exclusivamente em casa, privatizando, dessa forma, a nova identidade. Porém, à medida que o processo de conversão religiosa se afiança, é necessário dar o "pulo" - como denomina essa etapa o rabino Steinsaltz (1994), em clara referência à necessidade de optar, definitivamente, por um dos dois sistemas nos quais vivem os baalei teshuvá. É nessa fase que as leis dietéticas exercerão a função de reformular as fronteiras do grupo, estreitando o elenco de relações sociais permitidas, uma vez que os novos ortodoxos reduzem o seu círculo de amigos e as atividades de lazer, entre os quais a comida sempre tem e teve um papel fundamental. Assim, os encontros e as confraternizações se restringem a freqüentar espaços ortodoxos, sejam públicos ou privados.

Todavia, a convivência com outros segmentos da sociedade mais ampla, por mais limitada que seja, faz com que os baalei teshuvá sejam vistos - e se sintam - já não como os outros brasileiros, isto é, como simples comensais, e sim como judeus; fenômeno que revela o poder das leis dietéticas em colocar uma marca identitária definitiva. Isso tudo sugere que, 
entre os novos ortodoxos, o papel da comida como um dos elementos mais relevantes na conformação da nova identidade do sujeito é indubitável, e, como fora mencionado, constitui a sua afirmação perante os outros da adesão a um grupo étnico específico.

Focalizar a análise na dimensão ritual das leis dietéticas foi um exercício fecundo para demonstrar as suas múltiplas funções sociais. Cabe agora fazer uma pausa para incursionar num outro aspecto, o simbólico, que nos ajudará a compreender melhor por que o princípio da kashrut constitui um pilar no judaísmo ortodoxo.

\section{As leis dietéticas como metáfora, ou algumas reflexões sobre o sagrado no judaísmo}

Após a publicação do celebérrimo Purity and Danger (1966) de Mary Douglas, de cujos capítulos um está abocado ao estudo das leis dietéticas judaicas, outros textos da antropóloga tiveram como foco de indagação o mesmo fenômeno, ampliando, através de uma análise mais complexa, a sua compreensão. Com efeito, mais de quinze anos depois, num outro texto, denominado Deciphering a Meal (1984), o que chama a atenção de Douglas é que, se na maioria das culturas, os sistemas que classificam animais em puros e impuros refletem padrões de regras que governam relações humanas, estabelecendo uma equivalência entre relações sexuais e gastronômicas, no judaísmo é impossível estabelecer esse paralelismo. Dizendo de outro modo, hoje sabemos que numerosas sociedades projetam no reino animal categorias e valores que correspondem às categorias das pessoas com as quais está permitido casar, fazendo com que as categorias sociais de descendência e afinidade dominem as categorias naturais (Douglas, 1984, p. 262). Todavia, não se observa nenhuma preocupação similar na rígida taxonomia judaica em relação aos princípios de pureza e impureza, o que coloca um interrogante no que diz respeito a quais são as ansiedades expressadas nas leis dietéticas judaicas. Esse interrogante torna-se mais aguçado se partirmos do pressuposto que muito tem mudado no código legal judaico ortodoxo ao longo dos séculos, ao contrário do acontecido com as leis dietéticas que ficaram imutáveis, isto 
é, idênticas a como aparecem na Bíblia hebraica, mais precisamente, nos livros Levítico e Deuteronômio. ${ }^{15}$

A resposta de Douglas a este quebra-cabeça é que uma analogia diferente da encontrada em outras culturas entre a cama e a mesa sobressai no judaísmo: a da mesa e o altar. Assim, da mesma forma que em Purity and Danger, a idéia central da análise se mantém, e a singularidade das leis dietéticas judaicas radica em abominar criaturas anômalas, tanto aquelas que vivem em duas esferas (terra e água), como as que têm características de uma outra esfera, ou as que adolescem de traços distintivos (dentre as quais, o porco seria o exemplo paradigmático). Mas a inovação desse texto, no qual a autora transcende a análise exclusivamente racional da taxonomia judaica, para incursionar no seu aspecto simbólico e na sua importância na configuração das relações sociais do grupo, se revela nas conclusões. Nas palavras de Douglas (1984, p. 266):

Todo ser vivo que fica fora desta classificação não deve ser tocado ou consumido. Tocar implica ser contaminado e nenhum tipo de poluição pode entrar no templo. Assim, pode se resumir de forma razoável dizendo que as criaturas anômalas são impróprias tanto para o altar quanto para a mesa. Esta é a peculiaridade do código mosaico. ${ }^{16}$

A esses critérios deve-se acrescentar que as teorias sobre poluição constituem, basicamente, tentativas de resolver conflitos sociais, degradando ou excluindo um setor da população. De fato, diversas etnografias têm demonstrado que idéias relativas à poluição são fundamentais na manutenção dos códigos social e moral aceitos por uma sociedade, ao mesmo tempo em que separam em categorias hierárquicas seus membros (Douglas, 1993/ 4). Observamos a concretização desse princípio na classificação da população da Índia em castas, e na segregação de leprosos e aidéticos, ou de mulheres por homens, em inúmeras culturas. Da perspectiva desses siste-

\footnotetext{
${ }^{15}$ É necessário esclarecer que as leis dietéticas permaneceram imutáveis no sentido de que o acréscimo de interdições obedece exclusivamente aos avanços tecnológicos na área dos alimentos e sua preparação, e não à uma reinterpretação do princípio da kashrut.

${ }^{16}$ No original: Any living being which falls outside this classification is not to be touched or eaten. To touch it is to be defiled and defilment forbids entry to the temple. Thus it can be summed up fairly by saying that anomalous creatures are unfit for altar and table. This is a peculiarity of the Mosaic code. (Tradução minha).
} 
mas, as leis sobre poluição tentam proteger a sociedade de alguns de seus membros (geralmente, grupos), que são considerados uma ameaça.

Em contraposição, o judaísmo nos confronta, mais uma vez, com uma atipicidade: as leis dietéticas, bem como todo o arcabouço legal judaico relativo aos princípios de pureza e impureza, são universais, isto é., regram a vida de todos os membros da comunidade. Conseqüentemente, elas não têm como objetivo estabelecer demarcações sociais no seio do grupo. E aqui vale a pena salientar a insistência do autor do Levítico em lembrar que também o pobre e o estrangeiro devem ser incluídos nas exigências da Lei, e não só judeus e judias - sejam pobres ou ricos, sacerdotes ou pessoas comuns. Finalmente, no judaísmo, a poluição é sempre um estado transitório - nunca uma condição estrutural -, e todo aquele que foi contaminado tem o direito à expiação ou purificação. Como conclui Douglas (1993/4, p. 113-114), muitas das leis encontradas no Levítico ajudam a sustentar um código moral, porém, nada nelas apóia uma estratificação social.

Mas, qual o substrato desse código moral, e qual seu objetivo último? Após uma análise minuciosa do Levítico, Douglas (1993/4) compartilha conosco um achado: a existência de um paralelismo nas leis judaicas relativas ao puro e ao impuro que faz com que tanto os animais, como os seres humanos ou o altar, possam ser considerados kasher ou não-kasher. É esse o caminho que levará a antropóloga a concluir que o corpo é uma metáfora do santuário. (1993/4, p. 121). O exemplo que se segue constitui uma ilustração da teoria de Douglas. Assim, o homem pio que ingere, por exemplo, uma ave predadora que tem-se alimentado de sangue, é imediatamente contaminado, como se ele próprio tivesse ingerido sangue; da mesma forma que introduzir carne não kasher no corpo daquele que fará uma oferenda equiivale a contaminar o santuário. Poder-se-ia ir um pouco mais longe até, e afirmar que toda a estrutura do livro tem como missão nos explicar a função do santuário que, segundo a autora, é proteger a justiça e a bondade divinas. Todavia, numa sociedade de pequenos pastores e agricultores, é impossível pensar em indivíduos perfeitos, isto é, a priori e definitivamente kasher. Eis a necessidade das leis sobre pureza e impureza! Tentar restabelecer possíveis desvios e colocar instrumentos para purificar aqueles que cometerem infrações - voluntária ou invountariamente -, ou que por alguma razão, entraram no estado transitório de impureza, e constituem uma ameaça de contaminação do Templo, símbolo central no monoteísmo ético judaico. 
Finalmente, e a modo de conclusão, nada melhor do que citar a própria Mary Douglas. Assim,

O corpo é um microcosmo teológico: o corpo que está maculado, sangrando, exudando, supurando, dilacerado, ora apresentado como uma mulher, ora como um homem, ora como uma roupa, em seguida como uma casa, depois como um sacerdote imperfeito, posteriormente como uma oferenda inadequada, chegando finalmente ao clímax como o santuário poluído, é a imagem de Israel na condição terrível em que poderia estar, se não consagrada. Esta é uma teologia negativa na sua forma mais convincente (Douglas, 1993/4, p. 129). ${ }^{17}$

No entanto, não se pode deixar de observar que se bem as leis dietéticas permaneceram imutáveis durante milênios, a estrutura social do povo judeu sofreu transformações radicais. Além do mais, o advento da modernidade, com a decorrente emancipação dos judeus nos estados-nação europeus teve, como um de seus efeitos mais significativos, o fim do judeu como substantivação, e o aparecimento de diversas formas de identidade judaica, cuja característica é a qualidade de judeu como adjetivação (Sacks, 1993). Um modo de se colocar isto nos termos do jargão antropológico é referir ao nascimento de identidades hifenizadas. A modo de ilustração, encontramos judeus-laicos, judeus-ortodoxos, judeus-brasileiros, judeus-reformistas, judeus-culturais, novos ortodoxos, só para mencionar algumas das possibilidades mais difundidas nos dias de hoje. Essa situação, como não poderia ser de outra maneira, leva a uma compreensão diferenciada das leis dietéticas por parte dos diversos grupos, que vai desde repudiá-las completamente, até segui-las à risca.

Observamos, ao longo do texto, os modos através dos quais os novos ortodoxos incorporam as leis dietéticas na sua cotidianidade, como as manipulam e as tensões que tal fenômeno acarreta. Faltava-nos, no entanto, instrumentos para compreender a sua centralidade no judaísmo. Acredito

${ }^{17}$ No original: The body is a theological microcosm: the blemished, bleeding, leaking, suppurating, torn body, now presented as a woman, now a man, now as a garment, then a house, now as an imperfect priest, now an inadequate offering, and then climaxing as the sanctuary defiled, is an image of Israel in the horrible condition she would be in, if unsanctified. This is negative theology at its most cogent). (Tradução minha).

Horizontes Antropológicos, Porto Alegre, ano 9, n. 19, p. 203-222, julho de 2003 
que após a análise desenvolvida, estamos em condições de preencher esta lacuna.

Assim, as leis dietéticas cumprem duas funções: santificam os judeus, analogamente a como o Templo era santificado, e estabelecem limites rígidos que separam insiders de outsiders, fenômeno que da perspectiva da ortodoxia, evita a ameaça da assimilação, com o decorrente desaparecimento do povo judeu. Foi isso o que expressou o rabino anteriormente citado ao se referir à importância de "viver kasher". Nesse sentido, manter as fronteiras da comunidade judaica através do respeito às leis dietéticas é a conclusão à qual chega Mary Douglas (1984, p. 269), quando afirma:

A santidade dos limites cognitivos se faz conhecer através da integridade das formas físicas. Os exemplares físicos perfeitos apontam à perfeição dos limites do templo, do altar, do santuário. E estes, consequentemente, indicam a grande dificuldade em conquistar e defender os limites territoriais da Terra Prometida. ${ }^{18}$

O mais claro exemplo que revela a obrigação de os judeus se santificarem, isto é, de serem tmeim (puros) para cumprir a vontade divina de transformar-se num povo de sacerdotes, aparece nos versos que dão início a todas as bênçãos, incluídas as que antecedem a ingestão de alimentos: "Bendito sejas Tu, ó Eterno, nosso Deus Rei do mundo, que nos santificaste em teus mandamentos".

E aqui é importante salientar que, destruído o Templo e perdida a Terra Prometida, o judaísmo transformou-se de uma religião sacrificial em uma eminentemente ritualizada, que colocou uma ênfase ainda maior na necessidade de que todos os membros do grupo seguissem à risca as leis dietéticas. Mas, no momento em que o judaísmo fica dividido e, principalmente, quando entram em cena os baalei teshuvá ou novos ortodoxos, a função das leis dietéticas se vê em grande parte tergiversada quando uma mãe judia chora porque seu filho não pode consumir as suas delícias, ou quando judeus se vêem impedidos de freqüentar casas de outros judeus,

18 No original: The sanctity of cognitive boundaries is made known by valuing the integrity of the physical forms. The perfect physical specimens point to the perfectly bounded temple, altar, and sanctuary. And these, in turn, point to the hard-won and hard-to-defend territorial boundaries of the Promise Land. (Tradução minha). 
causando, como foi possível observar, constrangimentos para todas as partes. Perante esta novidade, o que realmente surpreende é o papel central do mercado na solução desse conflito. Assim, os cada vez mais difundidos restaurantes kasher - tanto em São Paulo como em outros lugares da diáspora - outorgam numerosas vantagens aos novos ortodoxos. Como bem observa Danzger ([s.d.], p. 467), nesses espaços o indivíduo não precisa comer sozinho comida fria ou em pratos descartáveis e, mais importante do que isso, se afirmar como judeu, uma vez que esses restaurantes lhe outorgam a possibilidade de partilhar uma refeição com - e como - todos os outros comensais, sejam eles judeus ortodoxos ou não-ortodoxos ou, inclusive, não judeus. Conseqüentemente, comer num restaurante kasher representa um alívio para as tensões que as rígidas leis dietéticas impõem aos baalei teshuvá, resolvendo a ambivalência sociológica discutida acima.

Um outro paradoxo, contudo, não pode escapar a qualquer olhar aguçado: o fato de que, no objetivo de se transformar em judeus pios, os novos ortodoxos tenham de sair do lar judaico, símbolo durante milênios das fronteiras do grupo e de sua identidade étnica, para, no seio da sociedade mais ampla, lograr serem bons judeus.

\section{Referências}

BELL, C. Ritual Perspectives and Dimensions. New York: Oxford University Press, 1997.

BÍBLIA de Jerusalém. São Paulo: Edições Paulinas, 1973.

BUCKSER, A. Keeping Kosher: Eating and Social Identity among the Jews of Denmark. Ethnology, v. 38, n. 3, 1999.

DANZGER, H. The meanings of Keeping Kosher: Views of the Newly Orthodox. Judaism: a Quarterly Journal of Jewish Life \& Thought. [s.d.]. DONIN, H. H. Guia para a observância judaica na vida contemporânea. Jerusalém: Organização Sionista Mundial, Departamento de Educação e Cultura Religiosa para a Diáspora, 1985.

ENDE, S. Ingerir carne e leite: de onde vem esta proibição. Chabad News, abr./jun. 1999.

ENDE, S. Bênçãos sobre alimentos: III As seis bênçãos anteriores aos alimentos. Chabad News, jan. 2001. 
DOUGLAS, M. Purity and Danger, an Analysis of Conception of Pollution and Taboo. London: Routledge and Kegan Paul, 1966.

DOUGLAS, M. Deciphering a Meal. In: IMPLICIT Meanings: Essays in Anthropology. London: Routledge \& Kegan Paul, 1984.

DOUGLAS, M. Atonement in Leviticus. Jewish Studies Quarterly, v. 1, 1993/4.

GIDDENS, A. As conseqüências da modernidade. São Paulo: UNESP, 1991.

GRUNBLATT, J. Thinking Kosher. [s.d.]. Disponível em: <http:// www.ou.org/kosher>. Acesso em: 2002.

MERTON, R. K.; BARBER, E. Sociological Ambivalence. In: TIRYAKIAN, E. A. Sociological Theory, Values, and Sociocultural Change: Essays in Honor of Pitirim Sorokin. New York, 1963.

SACKS, J. Orthodoxy Confronts Modernity. London: Ktav Publishing House, 1991.

SACKS, J. One People?: Tradition, Modernity and Jewish Unity. Washington: The Littman Library of Jewish Civilization, 1993.

STEINSALTZ, A. Teshuvá: um guia para o judeu recém-praticante. São Paulo: Editora Maayanot, 1994.

TOPEL, M. Do retorno ao passado e da construção do futuro: algumas observações sobre os baalei teshuvá de São Paulo. Cadernos de Língua e Literatura Hebraica, n. 3, 2003.

TOPEL, M. O movimento de teshuvá em São Paulo e o esgotamento do judaísmo secular no Brasil: algumas reflexões. In: V VOLUME de Judaica Latinoamericana. Jerusalém: Magnes Press. No prelo.

Recebido em 13/01/2003

Aprovado em 10/04/2003 